Marc Prohom and Oriol Puig ${ }^{49}$

\title{
18 Weather Observation Network and Climate Change Monitoring in Catalonia, Spain
}

\begin{abstract}
This paper details the weather and climate monitoring of the Meteorological Service of Catalonia. Following a general overview of the institution, the weather observation network is described, as is the importance of monitoring real-time phenomena efficiently. Finally, the procedures, methods and techniques for achieving reliable climate change monitoring are also described, paying particular attention to the importance of data rescue initiatives and the quality control and homogenization of climate data series. To summarize, the main characteristics of climate change experienced in Catalonia are shown, together with the results of climate projections for the near future.
\end{abstract}

Keywords: Climate projections, Lighting detector, Radar network, Radiosounding station, Weather stations

\subsection{Overview of SMC: History, Background and Characteristics}

The Meteorological Service of Catalonia (SMC, in its Catalan abbreviation) is a public sector company within the Generalitat (the autonomous government of Catalonia), with its own legal status. The SMC was established in 1921 by the "Mancomunitat", the Catalan governmental body that grouped together the four provinces of the region, with Eduard Fontserè being appointed the first director. Between 1921 and 1939, the main duty of the institution was weather forecasting, in order to provide improved forecasts of extreme weather conditions and information for certain sectors such as air transportation. During its seventeen-year existence, the SMC gave an extraordinary boost to meteorology in Catalonia, with some of its work proving to be of great scientific value and gaining international prestige. Among the projects with widespread impact outside Catalonia were the SMC's participation in producing the International atlas of clouds and of states of sky, its contribution to the International Polar Year (1932-33), by creating two mountain-top observatories, and its design of the Jardí rain gauge. However, in 1939 the SMC was closed down and its archives and belongings confiscated due to the Spanish Civil War.

Many years later, with the return to democracy in Spain, the 1979 Statute of Autonomy gave the Catalan government exclusive rights to reestablish the former

49 Meteorological Service of Catalonia, Barcelona, mprohom@meteocat.com 
meteorological service, and thanks to the 2001 Meteorological Law, the service once again became a reality. Since then, the main duties of SMC have been:

- Assisting public authorities and institutions in their needs for meteorological and climate information.

- Managing and maintaining the weather observation network.

- Operating the meteorological database of Catalonia.

- Programming, introducing and managing a system of forecasting and monitoring meteorological phenomena and climate change.

This paper shows the main tools and methods that the SMC uses to achieve such goals, i.e. its weather observation network and climate change monitoring system.

\subsection{Weather Observation Network}

Every day, thousands of atmospheric observations are made around the world, measuring several meteorological parameters in a variety of ways. In Catalonia, the SMC has developed a weather observation network that provides information on the current state of the weather, providing inputs to numerical forecasting models and information on the intensity, frequency and spatial distribution of extreme weather events. This chapter describes measurements made by the SMC at weather stations, both automatic and conventional, in the upper atmosphere, and via weather radar and lightning detection systems.

\subsubsection{Automatic and Conventional Land Weather Stations}

Surface observations are particularly important because they provide information about weather that is experienced by people and most of the socioeconomic environment. Two different networks are operated by the SMC: Automatic (AWS) and Conventional (or manual) Weather Stations (CWS).

At present (2012), 174 AWS cover the entire Catalan territory. Observations are made primarily for the purpose of providing information on the current state of the atmosphere for weather forecasting purposes. For this reason, they include measurements of a wide range of meteorological elements, have a uniform spatial distribution and cover the variety of climates found in the region, particularly the mountainous areas of the Pyrenees. A description on the technical specifications of the AWS is provided in Table 18.1.

The measurement of all elements is fully automated, with data being logged at the station and transmitted to a central system based at the SMC headquarters in Barcelona. Each station produces observations at one-minute intervals, and thirtyminute observations are then generated for onward real-time transmission to users worldwide via the SMC website. 
Table 18.1: Main technical characteristics of the elements of the AWS network (MR, Measurement Range and Acc, Accuracy).

\begin{tabular}{|c|c|c|c|c|}
\hline Element & Equipment branch/model & Technical specifications & $\begin{array}{l}\text { Height } \\
\text { (m) }\end{array}$ & $\begin{array}{l}\text { Num. of } \\
\text { elements }\end{array}$ \\
\hline Datalogger & Campbell Scientific/CR1000 & $\begin{array}{l}\text { Input voltage range: } 5 \mathrm{Vdc} \\
\text { Final storage: } 4 \mathrm{Mb}\end{array}$ & & 174 \\
\hline $\begin{array}{l}\text { Wind force and } \\
\text { direction }\end{array}$ & RMYoung/05103 & $\begin{array}{l}\text { MR: } 0-100 \mathrm{~m} / \mathrm{s} \\
\text { Sensitivity: } 1.0 \mathrm{~m} / \mathrm{s}\end{array}$ & $\begin{array}{l}2.0 \\
6.0 \\
10.0\end{array}$ & $\begin{array}{l}58 \\
13 \\
81\end{array}$ \\
\hline $\begin{array}{l}\text { Global solar } \\
\text { radiation }\end{array}$ & Kipp\&Zonen/CMP6 & $\begin{array}{l}\text { MR: } 285-2800 \mathrm{~nm} \\
\text { Sensitivity: } 5-20 \mu \mathrm{V} / \mathrm{W} / \mathrm{m}^{2}\end{array}$ & 2.0 & 43 \\
\hline $\begin{array}{l}\text { Temperature and } \\
\text { relative humidity }\end{array}$ & Vaisala/HMP155 & $\begin{array}{l}\text { MR: }-80-60^{\circ} \mathrm{C} \\
\text { MR: } 0-100 \% \\
\text { ACC: }-20 /+40^{\circ} \mathrm{C}\end{array}$ & 1.5 & 174 \\
\hline $\begin{array}{l}\text { Barometric } \\
\text { pressure }\end{array}$ & Vaisala/PTB110 & $\begin{array}{l}\text { MR: } 600-1100 \mathrm{hPa} \\
\text { Acc: } \pm 0.3 \mathrm{hPa} \text { at }+20^{\circ} \mathrm{C}\end{array}$ & & 72 \\
\hline Precipitation & $\begin{array}{l}\text { Lambrecht tipping bucket } \\
\text { Thies tipping bucket }\end{array}$ & $\begin{array}{l}\text { Acc: } 2 \% \\
\text { Resolution: } 0.1 \mathrm{~mm}\end{array}$ & 1.4 & $\begin{array}{l}72 \\
88\end{array}$ \\
\hline $\begin{array}{l}\text { Accumulated } \\
\text { precipitation }\end{array}$ & $\begin{array}{l}\text { Geonor/T200B Vibrating-wire } \\
\text { weighing transducer }\end{array}$ & $\begin{array}{l}\text { Capacity: } 600 \mathrm{~mm} \\
\text { Sensitivity: } 0.05 \mathrm{~mm} \\
\text { Acc: } 0.1 \% \mathrm{FS}\end{array}$ & 2.0 & 11 \\
\hline Snow depth & $\begin{array}{l}\text { Campbell Scientific/SR50A } \\
\text { Acoustic sensor }\end{array}$ & $\begin{array}{l}\text { MR: } 0.5 \text { to } 10 \mathrm{~m} \\
\text { Acc: } \pm 1 \mathrm{~cm}\end{array}$ & 3.0 & 18 \\
\hline Soil temperature & Campbell Scientific/107 & $\begin{array}{l}\text { MR: }-35^{\circ} \mathrm{C} \text { to }+50^{\circ} \mathrm{C} \\
\text { ACC: } \pm 0.2^{\circ} \mathrm{C}\left(0^{\circ} \text { to } 50^{\circ} \mathrm{C}\right)\end{array}$ & $\begin{array}{l}-0.05 \\
-0.50\end{array}$ & $\begin{array}{l}38 \\
35\end{array}$ \\
\hline
\end{tabular}

Although most of the observation process today is automated, a network of 135 CWS provide additional data that is not reported by AWS. This network is called XOM (Catalan abbreviation of Meteorological Observers Network) and is formed by trained and enthusiastic meteorological observers who also provide estimates of elements that are hard to automate, such as visibility, cloud cover and meteors, while also reporting any severe weather events in near real time, i.e. heavy snowfalls, hailstorms, tornadoes, etc. Figure 18.1 shows the spatial location of both networks. Many CWS are maintained to meet the requirements for accurate climate averages at a wide variety of locations around Catalonia. A long uninterrupted record is essential for this purpose (at least 30 years and preferably longer) and this is achieved at a large number of stations. 


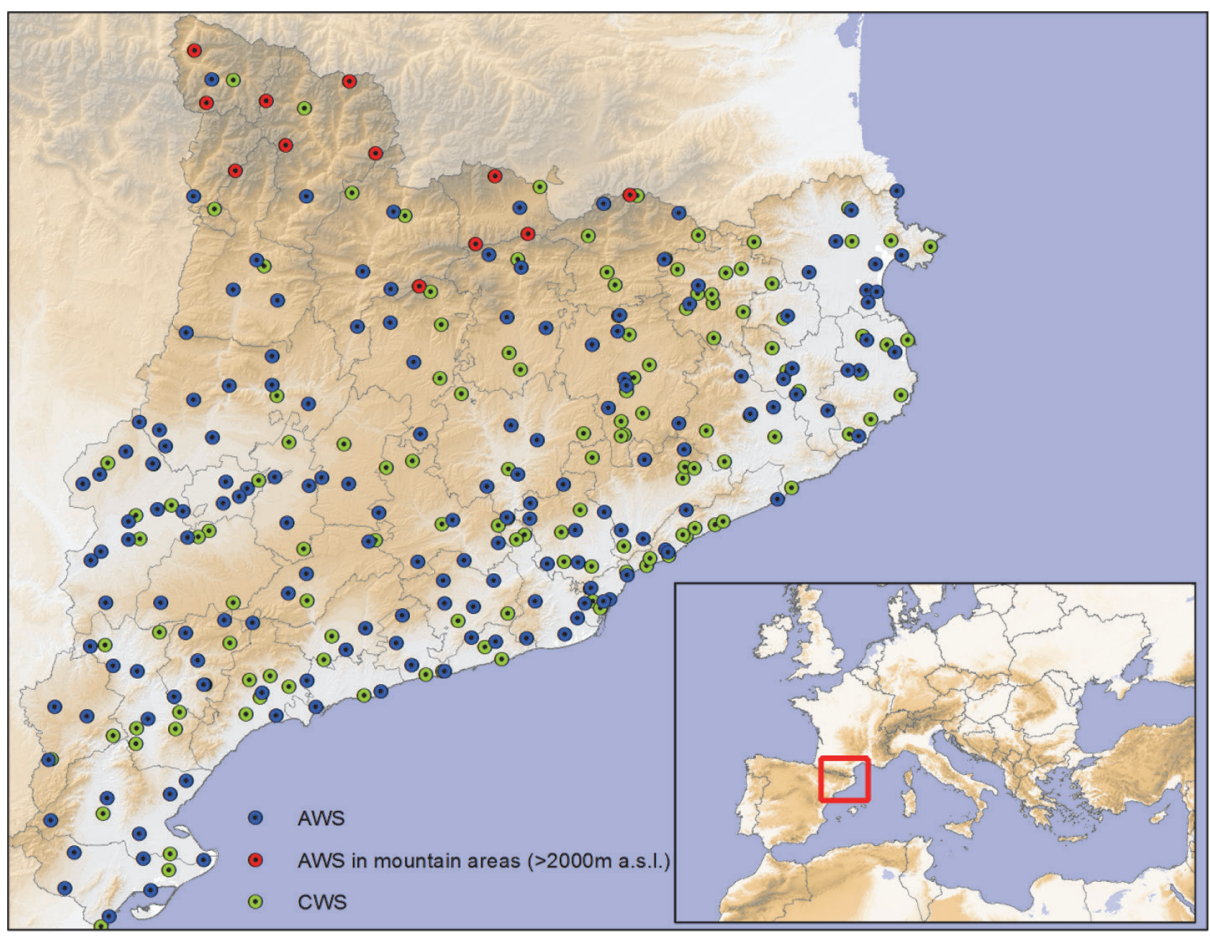

Figure 18.1: Spatial distribution of AWS (in blue) and CWS (in green) operated by SMC, distinguishing high mountain AWS (in red).

\subsubsection{Radar Network}

Meteorological radars are observation instruments which allow rainfall and its likely intensity to be detected from a great distance. This makes radars an essential tool for monitoring and forecasting extremely heavy rainfall, thus minimizing the effects of downpours on people and property. The radar network of the SMC (XRAD) is composed of four systems, which are Doppler type and operate in C band (5600 to $5650 \mathrm{MHz}$ ), with a $240 \mathrm{~km}$ observation radius and a $1 \mathrm{~km}$ resolution. All the radar systems generate a new volume of data every 6 minutes, and each one is composed of three tasks: the first one, with a range of more or less $250 \mathrm{~km}$ and the lowest elevation, is generated for surveillance purposes, while the remaining two (range between 130 and $150 \mathrm{~km}$, and seven elevations to each one) scan practically the whole troposphere with the purpose of collecting data for generating a precise rainfall estimation, and for the characterization of the vertical development of echo structures (Bech et al. 2004). Data are collected in polar coordinates, but most of the products are converted into a Cartesian grid. As well as rainfall, mountains also return the energy received from radar systems. As a result, in mountainous areas such as Catalonia, these features have to be taken into consideration when designing the structure of a radar network. Fixed echoes and 
other associated problems (attenuation, occultation, anomalous propagation, bright band, etc.) require a series of subsequent corrections to be made, especially if a quantitative use of the radar-produced observations is desired.

\subsubsection{Lightning Detection Network}

The sum of intracloud (IC) and cloud-to-ground (CG), known as the total lightning data, is determined by the Lightning Detection Network (LDN) operated by the SMC since 2003. The LDN covers Catalonia with an efficiency of more than $90 \%$. It is currently composed of four Vaisala LS-8000 total lightning detectors. IC and CG flashes are detected and processed separately. On one hand, IC flashes are detected in the VHF (110 to $118 \mathrm{MHz}$ ) and located using interferometry (Lojou and Cummins 2006). On the other hand, CG return strikes, and are mainly observed by a low frequency (LF) sensor and located using a combination of the TOA/MDF (Time-of-Arrival/Magnetic Direction Finding) techniques (Cummins et al. 1998).

The SMC LDN is an important step forward in the real-time detection of thunderstorms and the short-term forecasting of their course. This tool gives support for surveillance meteorological tasks and complements other tools such as satellites, weather radar networks and AWS (Figure 18.2). Lightning data adds information to this characterization and can define the most active storms, benefiting a wide range of users such as power companies, telecommunication networks, major infrastructures, outdoor leisure complexes, etc.

\subsubsection{Automatic Radiosounding Station}

The radiosounding system allows for an understanding of atmospheric conditions by measuring pressure, temperature, relative humidity and wind speed and direction from the ground to heights of more than $15-20 \mathrm{~km}$. This information is of particular importance for diagnosing highly-unstable meteorological conditions which can cause intense precipitation. Since April 1998, radiosounding has been carried out twice a day (at 00.00 GMT and 12.00 GMT) at the University of Barcelona (in collaboration with the Department of Astronomy and Meteorology), and since 2008 this system has been part of the World Meteorological Network (08129 code). Numerical weather prediction models need this information for their initialization as they work with data from the ground, as well as from more than 20 atmospheric layers at altitudes of up to $15,000 \mathrm{~m}$. Data from these soundings is entered daily into mesoscale numerical models operating at the SMC, and provides a substantial improvement in forecasts for Catalonia. Since December 2012, the system has been fully automated, with weather balloons and radiosondes being launched without the presence of a technician (Figure 18.3). 


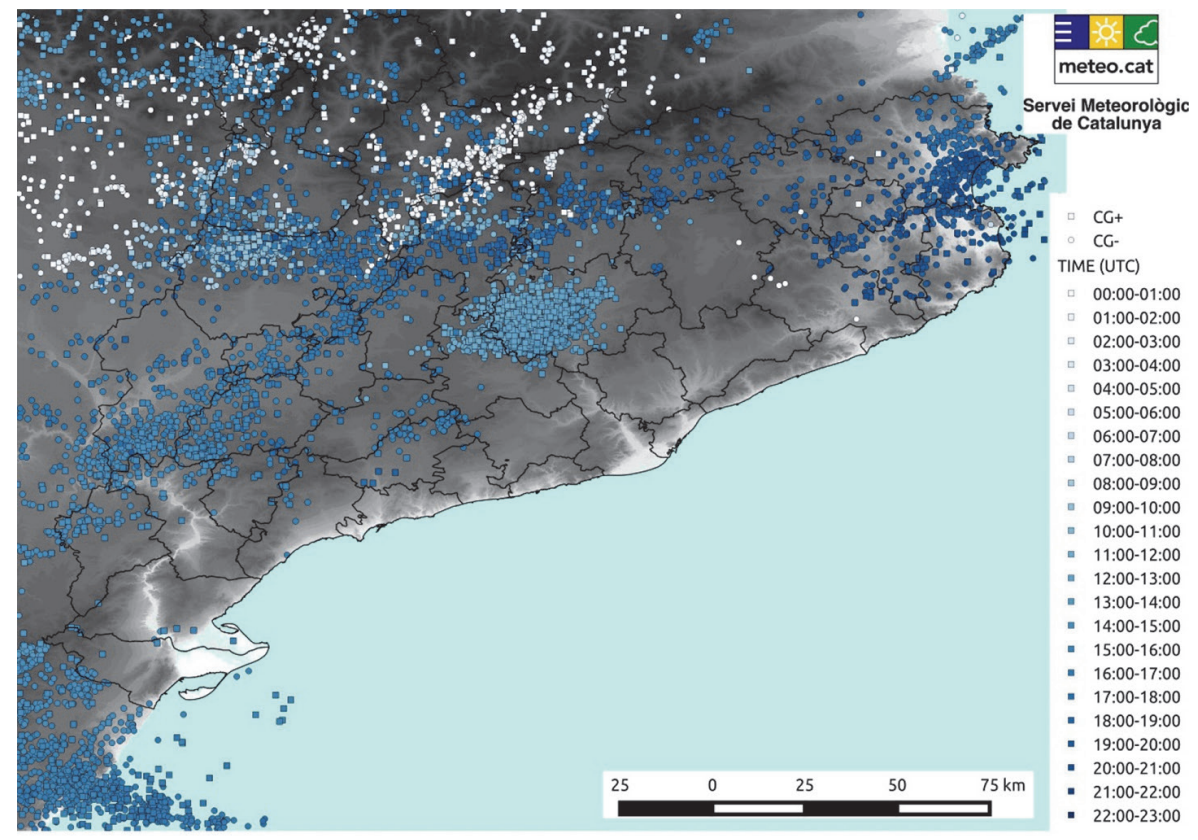

Figure 18.2: Lightning discharges map for a single day, $5^{\text {th }}$ July 2012. Source: Meteorological Service of Catalonia.

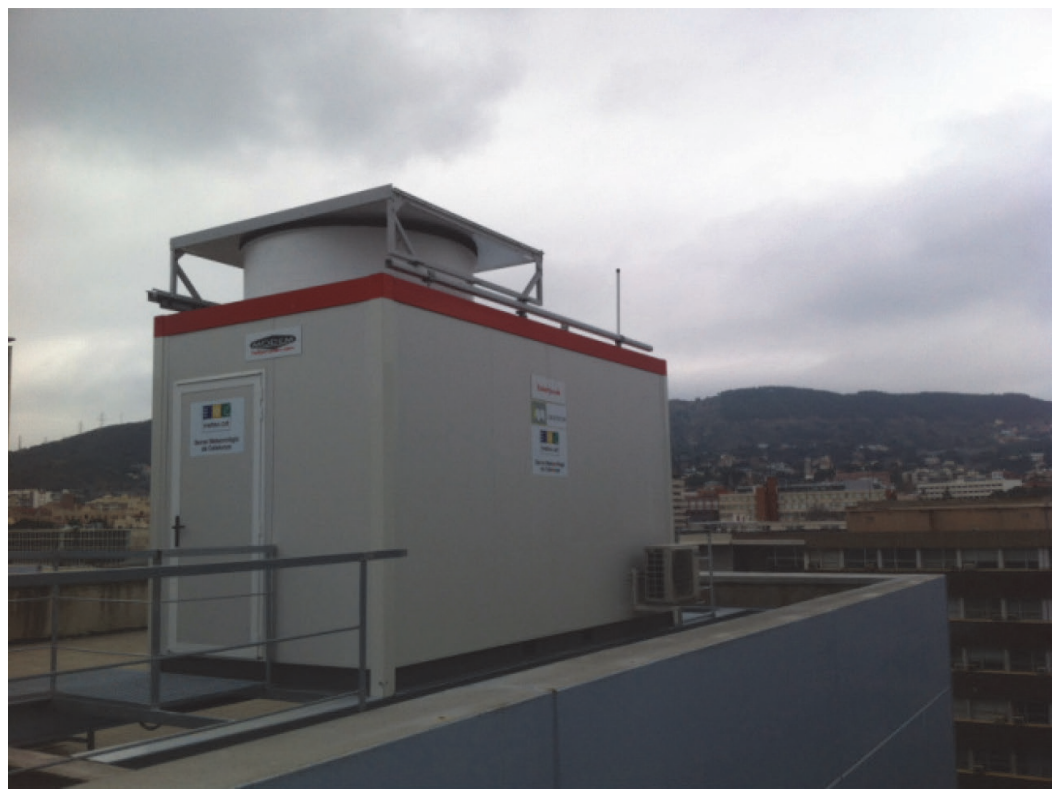

Figure 18.3: Automatic Radiosounding Station located on the roof of the Faculty of Physics (University of Barcelona). 


\subsection{Climate Change Monitoring and Future Projections}

The SMC issues its Climate Indicator Bulletin (CIB) every year, which details the latest status of climate change and variability in Catalonia. This report aims to help readers such as policymakers and researchers obtain a better understanding of climate evolution and therefore take measures to prevent global warming and to protect the environment. Where long-term records exist, it is possible to describe how current conditions fit into the long-term context of a variable and changing climate. What is more, the same records can be used to build and test the systems used to make long-term climate predictions. For this reason, in order to obtain a reliable view of the current climate, it is necessary to have long, quality-controlled and homogeneous climate series with sufficient spatial coverage. The steps to achieve these goals are described below.

\subsubsection{Data Rescue}

Developing data rescue initiatives is of special interest for the SMC. Since 2008, several projects have been undertaken in order to obtain long-term and high-quality instrumental records, focusing on: (1) detecting new long-term mountain climate series (>1,500 m above sea level) in historical archives; (2) improving temporal coverage of currently available records, i.e. filling gaps; and (3) recovering metadata information from different sites (see Aguilar et al. 2003 for more information on metadata). More than 1,500 daily climate records have been detected, encompassing the period from 1780 up to the present, measuring mainly temperature and precipitation. Among them, the works carried out to recover the climate records of Barcelona (since 1780), which are the most complete and oldest climate records of the Iberian Peninsula, are particularly relevant (Prohom et al. 2012) (Figure 18.4). Data rescue initiatives have also centered on reconstructing extreme events, i.e. heavy snowfalls, thus providing knowledge of the spatial distribution and frequency of such phenomena. Finally, the SMC also participates in several data rescue forums on an international level, such as Mediterranean Climate Data Rescue (MEDARE) and the EUMETNET Data Rescue Program (EUMETNET-DARE).

\subsubsection{Quality Control}

Data quality control is defined as a system of checks to assess and maintain the quality of a climate series. Quality control is simply a matter of comparing measured and expected values, i.e. what is acceptable, before a value is presumed to be suspicious or an error. Quality control procedures are designed to ensure data consistency, integrity, correctness and completeness, and also to identify and address errors and 


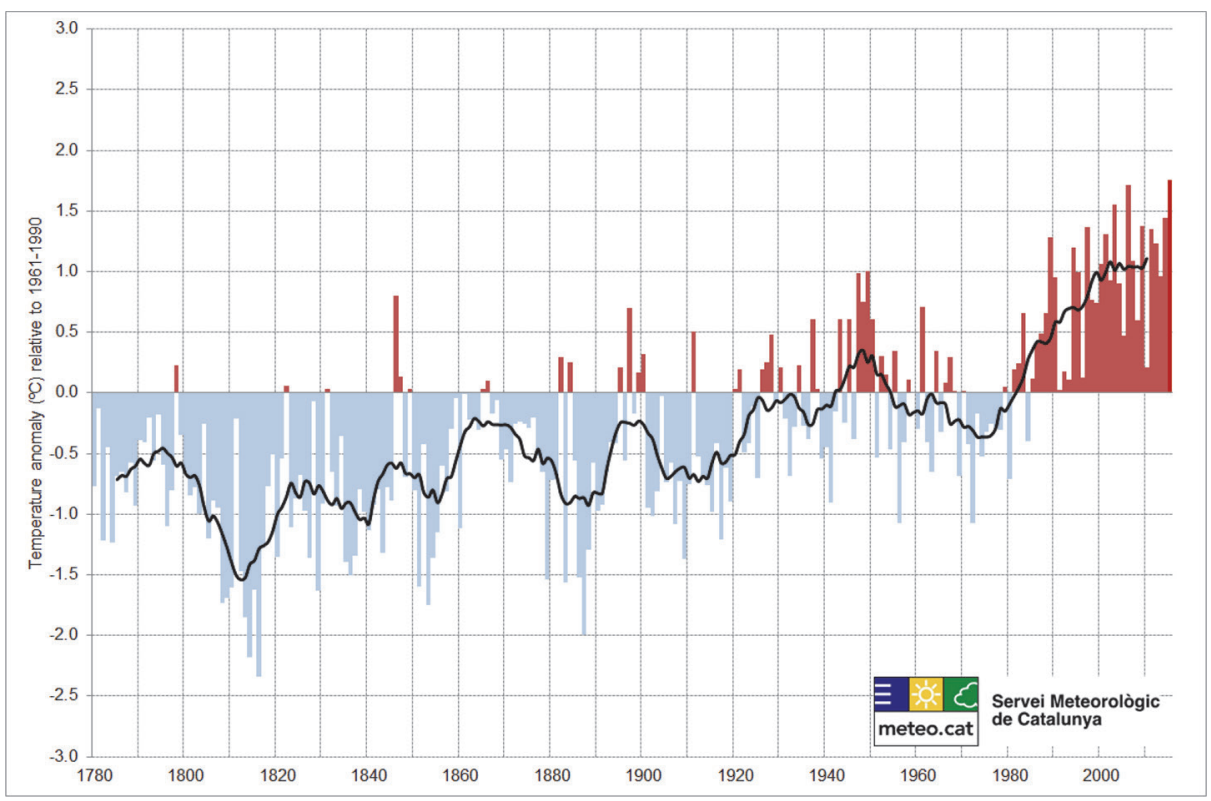

Figure 18.4: Mean yearly temperature in Barcelona (1780-2015) expressed as anomalies taking 1961-1990 as the reference period. The dark curve corresponds to an 11-year moving average.

omissions. This step is essential in detecting likely outliers, and to correct, confirm or remove them from the series.

As an example, on a daily scale for temperature the following checks are monitored: (1) Gross errors $\left(45^{\circ} \mathrm{C}>\right.$ Temperature $\left.<-15^{\circ} \mathrm{C}\right)$; (2) Internal coherency (Maximum temperature $\geq$ Minimum temperature), excessive leaps between two consecutive daily values $\left(>25^{\circ} \mathrm{C}\right.$ ) and flatline detection (more than 5 consecutive days with the same value); (3) Temporal coherency (more than 4 times the standard deviation and 3 times the interquartile range compared to climatological values); and (4) Spatial coherency (spatial representation of the same element to detect excessive differences in comparison to highly correlated values and nearby stations). Values within these thresholds are flagged as suspicious, checked against the original sources where possible, and finally removed or confirmed. With a visual inspection of the data, gross errors can also be detected.

By means of quality control, false inhomogeneities are eliminated and a homogeneity analysis is made without inferences.

\subsubsection{Homogeneity Analysis}

As previously said, the accuracy of climate observations is often affected by inhomogeneities due to changes in the technical or environmental conditions of measure- 


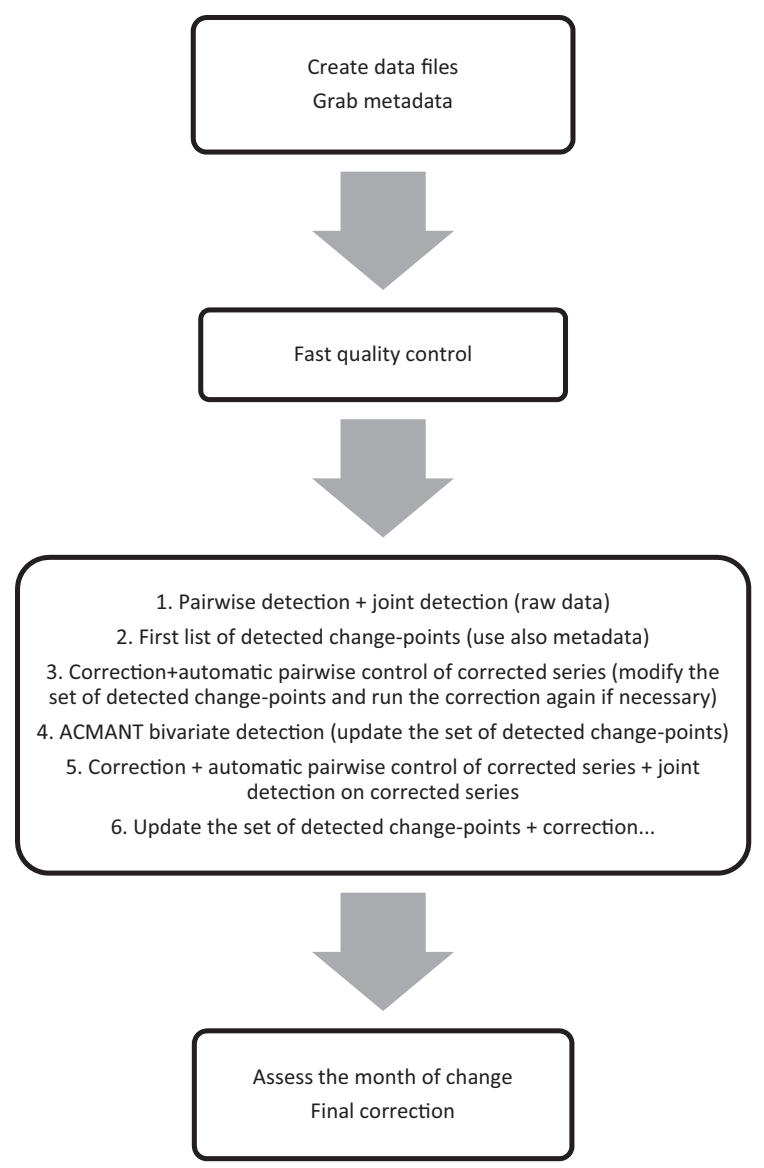

Figure 18.5: Task flow chart from HOMER.

ments (Auer et al. 2005). Most of these changes cause sudden shifts (break-points) in the series of local climate data, while others result in gradually increasing biases from real macroclimatic characteristics (urban development). As a result, the correction of inhomogeneities is highly recommended before any climate analysis is performed.

Among the large number of methods developed, the SMC has adopted HOMER as the procedure to homogenize instrumental series, as it includes the best features of other methods, namely PRODIGE, ACMANT and CGHSEG (Mestre et al. 2013), which have been ranked among the best methods for homogenizing monthly and annual climate data (Venema et al. 2012). HOMER provides a fast quality control of data, including an interactive semiautomatic method that combines three detection algorithms (pairwise-univariate detection, joint detection and ACMANT-bivariate detection), while ANOVA is used for correction (Figure 18.5). At a daily scale, as adjustments present a new level of complexity that are due mainly to the high variability 
inherent in daily data and the potential need for individual adjustments to each day, SMC has adopted the approach proposed by Vincent et al. (2002), whereby monthly adjustments made by HOMER are linearly interpolated to the daily scale, thus preserving trends and variations found in the homogenized monthly series.

These two homogeneity methods provide a reliable view of climate variability and change in Catalonia, both for trends of means (monthly, seasonal and annual scales) and extremes (daily scale).

\subsubsection{Recent Climate Trends Detected in Catalonia}

The results of how climate is changing in Catalonia are provided by the yearly Climate Indicators Bulletins (CIB). These reports have different chapters depending on the element analyzed: air temperature, precipitation, sea level rise, sea surface temperature, and climate extremes. For most of the elements, the analysis data ranges from 1950 to the present day, but for some series includes a wider time window (from 1905) or shorter one (for sea measurements). Below is a brief description of the CIB results, but for a more detailed, accurate study, the complete report can be downloaded from the SMC website (www.meteo.cat).

For temperature, a significant overall annual increase in mean air temperature in Catalonia has been detected since 1950, at a rate of $0.2^{\circ} \mathrm{C} /$ decade. Summer is the season recording the highest increases $\left(+0.33^{\circ} \mathrm{C} /\right.$ decade $)$, while autumn experiences a lower warming rate $\left(+0.15^{\circ} \mathrm{C} /\right.$ decade $)$. Maximum temperatures have a greater warming trend than minimum temperatures $\left(0.25^{\circ} \mathrm{C} /\right.$ decade vs. $0.15^{\circ} \mathrm{C} /$ decade $)$. As for precipitation, no conclusive remarks can be indicated, but as a whole a slight downward trend has been detected in mean annual precipitation since 1950, namely $-1.2 \%$ / decade, but without reaching the significant level of 95\% (Figure 18.6). A significant increase in sea-level temperature has also been noted since the start of measurements in 1974 , namely $0.3^{\circ} \mathrm{C} /$ decade, and the sea level has risen at a rate of $3.6 \mathrm{~cm} /$ decade, but over a shorter period, i.e. 1990-2012.

Several climate indices have been calculated using 20 daily homogenized temperature series (1950-2012) and following the criteria of the Expert Team on Climate Change Detection and Indices (ETCCDI) (http://www.clivar.org/organization/etccd). As a whole, all series indicate an increase in indices, thus reflecting a warming trend, i.e. warm nights and days, tropical nights, warm spell duration index and growing season length, while the opposite is experienced for indices indicating colder conditions, i.e. frosty days, icy days, cold nights and cold days. Indices for precipitation are calculated only for two long-term series located in Barcelona and Tortosa (southernmost part of the region), with daily high-quality data available since 1913 and 1905, respectively. No noteworthy results have been found, but a slight increase in days with heavy precipitation (for example, annual account of days when precipitation $\geq$ $50 \mathrm{~mm}$ ) and in the Simple Daily Intensity Index has been detected. 


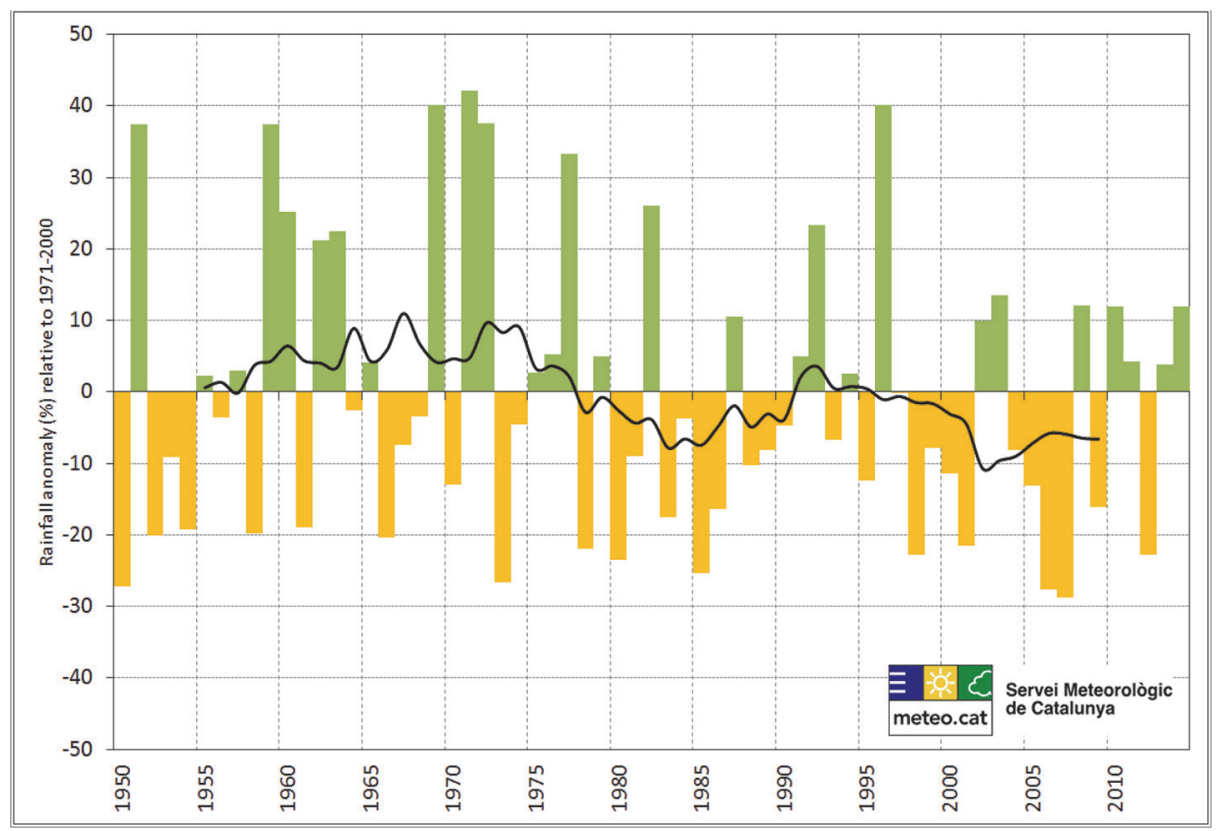

Figure 18.6: Mean annual rainfall in Catalonia obtained as from an average of 68 records over the period 1950-2014. Data is expressed as \% anomalies, taking 1971-2000 as the reference period. The dark curve corresponds to an 11-year moving average.

\subsubsection{Climate Projections in Catalonia (2001-2050)}

Efficient monitoring of recent climate is essential for a better understanding of future climate scenarios. Following this statement, the SMC promotes the ESCAT project (Climate Scenarios in Catalonia, Gonçalvez et al. 2014), that derives present time (1971-2000) and future (2001-2050) surface air temperature and precipitation trends for the North Western Mediterranean Basin using dynamical downscaling techniques at high resolution, $10 \mathrm{~km}$. Simulations use the Advanced Research Weather Research and Forecasting (WRF-ARF) model version 3.2.1 (Skamarock and Klemp 2008) and represent the three main families of emission scenarios defined in the IPCC-SRES (Nakićenović et al. 2000): A1B (rapid economic and population growth in a globalized world, with introduction of new and more efficient technologies and a balanced use of resources); A2 (divided world characterized by rapid and regionalized economic development, with few technological change and continued population growth); and B1 (a globalized world where environmental policies are promoted, economic development is not a priority, population increases, but not as much as in the A2 scenario). The Spain02 dataset (Herrera et al. 2012) is chosen for model assessment, as it provides surface daily maximum, minimum and range temperatures for Iberia and the Balearic Islands, over a regular grid of 0.2 o resolution. 
Projections show that temperature is expected to rise in all considered scenarios (up to $1.4 \mathrm{~K}$ for the annual mean), and particularly during summertime and in highaltitude areas. As for precipitation, annual mean precipitation is likely to decrease (around $-5 \%$ to $-13 \%$ in the most extreme scenarios). The climate signal for seasonal precipitation is not so clear, as it is highly influenced by the driving GCM (Global Circulation Model) simulation (Figure 18.7). All scenarios suggest statistically significant decreases of rainfall for mountain ranges in winter and autumn.
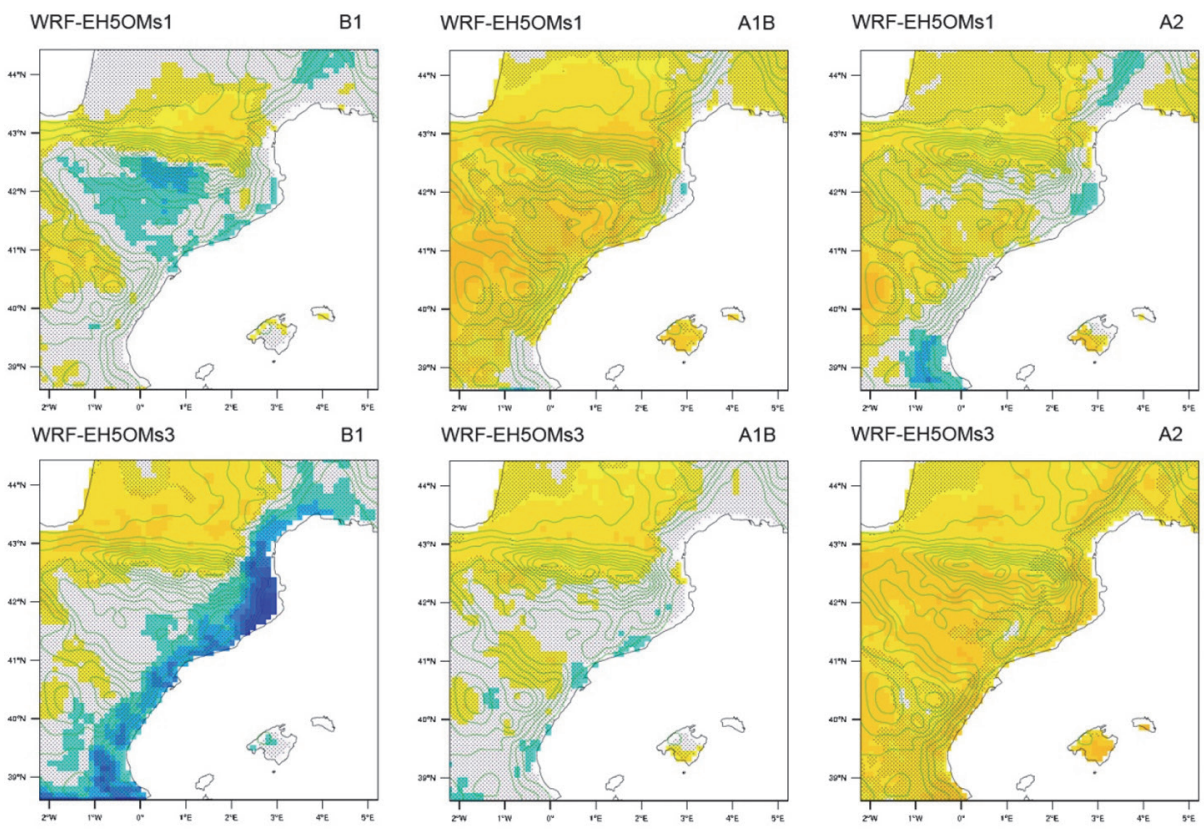

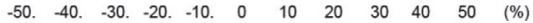

Figure 18.7: Differences in annual precipitation (\%) between 2021-2050 and 1971-2000 for Catalonia as projected by WRF-EH5OMs1 (upper panels) and WRF-EH5OMs3 (lower panels) for the B1, A1B and $A 2$ emission scenarios (from left to right).

A representative set of indices for temperature and precipitation extremes are also projected. The model's abilities to reproduce observed extremes are assessed for a control period (1971-2000) using the ERA40 reanalysis to drive the WRF-ARW simulations. The modelling system correctly reproduces the amplitude and frequency of extremes and provides a high degree of detail on variability over neighboring areas. However, it tends to overestimate the persistence of wet events and consequently slightly underestimates the length of dry periods (Barrera-Escoda et al. 2014). Drier and hotter conditions are generally projected for Catalonia, with significant increases in the duration of droughts and the occurrence of heavy precipitation events. The 
projected increase in the number of tropical nights and extreme temperatures could have a negative effect on human health and comfort.

\subsection{Conclusions}

The Meteorological Service of Catalonia (SMC) has legal status to foster research activities and improve awareness of meteorology and climatology throughout the region. Thanks to the observation network and the efforts made to collect high-quality and homogeneous climate series, as well as the application of robust and reliable analytical methodologies, these objectives are being achieved. Here we have seen an overview of the tools used, proving that in the future more research on climate and weather monitoring should be performed to provide better services and reliable information for citizens and policymakers, in order to better adapt to climate change and severe weather phenomena.

\section{References}

Aguilar, E., I. Auer, M. Brunet, T.C. Peterson, and J. Wieringa. 2003. WMO Guidelines on climate metadata and homogenization. WCDMP 53, WMO-TD 1186. Geneva: WMO.

Auer, I., R. Böhm, A. Jurkovic, A. Orlik, R. Potzmann, W. Schöner, M. Ungersböck, M. Brunetti, T. Nanni, M. Maugeri, K. Briffa, P. Jones, D. Efthymiadis, O. Mestre, J.M. Moisselin, M. Begert, R. Brazdil, O. Bochnicek, T. Cegnar, M. Gajic-Capka, K. Zaninivic, Z. Majstorovic, S. Szalai, T. Szentimrey. 2005. A new instrumental precipitation dataset in the greater alpine region for the period 1800-2002. International Journal of Climatology 25: 139-166.

Barrera-Escoda, A., M. Gonçalves, D. Guerreiro, J. Cunillera, and J.M. Baldasano. 2014. Projections of temperature and precipitation extremes in the North Western mediterranean basin by dynamical downscaling of climate scenarios at high resolution (1971-2050). Climatic Change 122: 567-582.

Bech, J., E. Vilaclara, N. Pineda, T. Rigo, J. López, F. O’Hora, J. Lorente, D. Sempere, and F.X. Fàbregas. 2004. The weather radar network of the Catalan meteorological service: description and applications. ERAD-European conference on radar in meteorology and hydrology- COST 717 Final seminar, ERAD publication, 416-420.

Cummins, K.L., M.J. Murphy, E.A. Bardo, W.L. Hiscox, R.B. Pyle, and A.E. Pifer. 1998. A combined TOA/MDF technology upgrade of the U.S. National lightning detection network. Journal of Geophysical Research 103: 9038-9044.

Gonçalves, M., A. Barrera-Escoda, D. Guerreiro, J.M. Baldasano, and J. Cunillera. 2014. Seasonal to yearly assessment of temperature and precipitation trends in the North Western mediterranean basin by dynamical downscaling of climate scenarios at high resolution (1971-2050). Climatic Change 122: 243-256.

Herrera, S., J.M. Gutiérrez, R. Ancell et al. 2012. Development and analysis of a 50 year high-resolution daily gridded precipitation dataset over Spain (Spain02). International Journal of Climatology 32, 74-85. doi:10.1002/joc.2256.

Lojou, J.Y., and K.L. Cummins. 2006. Total lightning mapping using both VHF interferometry and time-of-arrival techniques. 19th International Lightning Detection Conference, Tucson, USA. 
Mestre, O., P. Domokos, F. Picard, I. Auer, S. Robin, E. Lebarbier, R. Böhm, E. Aguilar, J. Guijarro, G. Vertachnik, M. Klancar, B. Gubuisson and P. Stepanek. 2013. HOMER: a homogenization software - methods and applications. Quarterly Journal of the Hungarian Meteorological Service 117, 1, 47-67.

Nakićenović, N., J. Alcamo, G. Davis et al. 2000. Emissions scenarios 2000-Special report of the Intergovernmental Panel on Climate Change (SRES). Cambridge University Press, Cambridge. http://www.ipcc.ch/ipccreports/sres/emission/index.php?idp=0.

Prohom, M., M. Barriendos, F. Aguilar, and R. Ripoll. 2012. Recuperación y análisis de la serie de temperatura diaria de Barcelona, 1780-2011. In Cambio climático. extremos e impactos, ed. C. Rodríguez-Puebla et al., 207-217. Salamanca: Spanish Association of Climatology. Isbn: 978-84-695-4331-3.

Skamarock, W.C., and J.B. Klemp. 2008. A time-split non hydrostatic atmospheric model for weather research and forecasting applications. Journal of Computational Physics 227: 3465-3485. doi: 10.1016/j.jcp.2007.01.037.

Venema, V., O. Mestre, E. Aguilar, I. Auer, J.A. Guijarro, P. Domonkos, G. Vertacnik, P. Stepanek, P. Zahradnicek, J. Viarre, G. Müller-Westermeier, T. Szentimrey, M. Lakatos, C.N. Williams, M. Menne, R, Lindau, D. Rasol, E. Rustemeier, K. Kolokythas, T. Marinova, L. Andresen, F. Acquaotta, S. Fratianni, S. Cheval, M. Klancar, M. Brunetti, C. Gruber, M. Prohom Duran, T. Likso, P. Esteban, and T. Brandsma. 2012. Benchmarking homogenization algorithms for monthly data. Climate of the Past 8: 89-115. doi: 10.5194/cp-8-89-2012.

Vincent, L.A., X. Zhang, B.R. Bonsal, and W.D. Hogg. 2002: Homogenization of daily temperatures over Canada. Journal of Climate 15: 1322-1334. 